\title{
Effects of Rainfall and Temperature Oscillations on Maize Yields in Buea Sub-Division, Cameroon
}

\author{
N. Balgah Sounders ${ }^{1}$, Tata Emmanuel Sunjo ${ }^{1} \&$ Mojoko Fiona Mbella ${ }^{1}$ \\ ${ }^{1}$ Department of Geography, University of Buea, Cameroon \\ Correspondence: Tata Emmanuel Sunjo, Department of Geography, University of Buea, Cameroon. Tel: \\ 237-675-955-929. E-mail: tataemmanuel@ymail.com
}

Received: September 21, 2016

Accepted: November 20, $2016 \quad$ Online Published: January 15, 2017

doi:10.5539/jas.v9n2p63

URL: http://dx.doi.org/10.5539/jas.v9n2p63

\begin{abstract}
There has been increasing concerns about the continuous variability in the climatic parameters of rainfall and temperature due to their manifold impacts. Some of these effects are observed through changes in crop yields such as maize in most parts of Sub-Saharan Africa which lacks the capital and technological viabilities to deal with the situation. This paper therefore examines the effects of the growing climatic oscillations on maize production. The study used primary and secondary data in order to provide insights on the quantitative effects of rainfall and temperature on maize yields in Buea Sub-Division. The climatic and crop trend analyses were done using simple regressions, means, and standard deviations. These were done using 2010 Excel Software. The impacts of varying rainfall and temperature on maize yields were determined using the logistic regression analysis in Stata 10 statistical software. Based on the analysis, results show that there has been growing rainfall and temperature fluctuations over Buea. This has been $\mathrm{x}$-rayed through the increasing temperatures, slight declines in rainfall amounts, and the unpredictability of the sensation and the departure of the rains. Other effects have been observed through short dry spells especially in the months of April as well as increasing flooding of some farmlands in the months of August and September. Results further show that the unpredictability of the commencement of the rains has shifted the sowing season of maize by an average of four weeks and because of this situation, maize yields have increased during the minor season more than yields in the main season. Other climatic impacts were observed through increasing maize attacks from pests and diseases. As the way forward, there is the need for the development of maize germplasms that are heat-tolerant and need for the concentration of maize in the second season when soil moisture to ensure maize seed germination, growth and maturity is assured.
\end{abstract}

Keywords: adaptations, Buea, Cameroon, pest-diseases, maize yields, rainfall and temperature oscillations

\section{Introduction}

Over one and the half centuries, the world has continued to witness growing concentration of greenhouse gases (GHG) largely from human activities such as industrialisation, deforestation and unsustainable agricultural activities. The results have been increasing climate change and variability and the associated impacts on human livelihoods. These climate change and variability scenarios observed through increasing temperatures, changing precipitation patterns, and increase in the frequency of climatic hazards (droughts and floods) have had untold impacts especially on the economies of developing countries that lack the required capital and technical packages to deal with the problem. Climatic models indicate that the future effects of these growing climatic changes will be more complicated if current changes continue unabated (IPCC, 2007). While the global distribution of the impacts ensuing from this growing unpredictable climatic conditions are more regionalised, the localisation of these change and variability effects present a herculean task in ensuring sustainable food security (Tata \& Lambi, 2015). One of the hardest hit sectors of the economies of the developing communities is agriculture. This is more so because agriculture especially in much of Sub-Saharan Africa is dominantly rain fed (Rao, Verchot, \& Laarman, 2007). With agriculture significantly contributing to the GDPs of these countries, the growing impacts of climate change and climate variability on agriculture could thus be a significant rupture to efforts of raising a significant number of populations of developing countries above the poverty line of less than one dollar per day. The changes in precipitation patterns alone will significantly increase the likelihood of crop failures such as maize and production declines (Nelson et al., 2009). 
After Cameroon gained independence in 1961, the government's involvement in the agricultural sector significantly increased the cultivation of crops especially cash crops which led to an increase in farmers' incomes. However, following the introduction of the Structural Adjustment Programmes (SAP) which reduced government intervention in a number of sectors of the Cameroonian economy as was the case with other developing countries in Africa by Breton Woods Institutions against the wishes of farmers and some politicians, farmers were left on their own and at the mercy of demand and supply market forces. This resulted in significant drops in the outputs and income from cash crops such as coffee and cocoa. The response from the farmers was the abandonment of these cash crops in favour of food crops such as maize, beans, and potatoes. Amongst these food crops, maize has remained one of the most widely cultivated crops. According to the Food and Agricultural Organisation Statistics (FAOSTAT, 2010), maize is produced on nearly 100 million hectares in developing countries, with almost $70 \%$ of the total maize production in the developing world coming from low and lower middle income countries such as Cameroon. Maize is the most important cereal that is cultivated in most parts of Sub-Saharan Africa.

In Buea Sub-Division like in most parts of Cameroon, maize is the principal staple food crop accounting for a significant proportion of calorie intake by the population. It does not only provide a sustained and secured food supply in terms of high yields, it also remains a significant boost to the income of the peasant farmers given that much of the maize yields are often sold in local and sub-regional markets. Thus, maize production provides a safety valve against frequent food insecurity which, most often, arises from climatic shocks such as droughts, floods and tornadoes, and climatically enhanced spread of pests and diseases. This is because, in the event of these climatic and climatic-assisted caprices, maize yields are often better off than yields of crops such as beans, potatoes, and a host of market gardening crops which are widely cultivated especially in the humid and sub-humid tropical Africa. Improving maize yields involves a combination of factors such as research on hybrid species, improving soil fertility through fertilizer application, and combating pests and diseases with the use of pesticides, insecticides and fungicides among others. However, even though climate plays a key underpinning role in maize yields, temporal variations in climatic parameters of rainfall and temperature could usher in direct and indirect adverse effects on maize production. Crop simulation models indicate that by 2050 in Sub-Saharan Africa, average rice, wheat, and maize yields will decline by up to 15,22 , and $10 \%$, respectively, as a result of climate change (IFPRI, 2009). In this regard, this study investigates the effects of such climatic oscillations on maize by using statistical analysis.

\section{Materials and Methods}

\subsection{The Study Area}

Buea Sub-Division is one of the Sub-Divisions that make up the Fako administrative area of Cameroon. The sub-division occupies a surface area of $870 \mathrm{~km}^{2}$ and is located between latitudes $4^{\circ} 12^{\prime}$ and $4^{\circ} 31^{\prime}$ North of the Equator and longitudes $9^{\circ} 9^{\prime}$ to longitude $9^{\circ} 12^{\prime}$ east of the Greenwich meridian (Mojoko, 2011). Buea Sub-division is bounded to the West by Mount Cameroon, to the east by Tiko Sub-Division, to the north by Muyuka Sub-Division and to the south by Limbe Sub-Division (Figure 1). The humid tropical climatic conditions alongside the rich volcanic soils provide ideal conditions for the cultivation of commercial crops mostly in plantations by the Cameroon Development Corporation as well as food crops by the local population. The area has unique topographic and geologic features due to its location on the eastern slopes of an active Mount Cameroon strato-volcano. Buea Municipality rest at an elevation of $1000 \mathrm{~m}$ above sea level on the south-eastern slopes of Mount Cameroon $(4095 \mathrm{~m})$, the highest in West Africa hosting a tan estimated population of over 176,000 inhabitants (Regional Institute of Statistics, Buea cited in Tosam, 2012). 


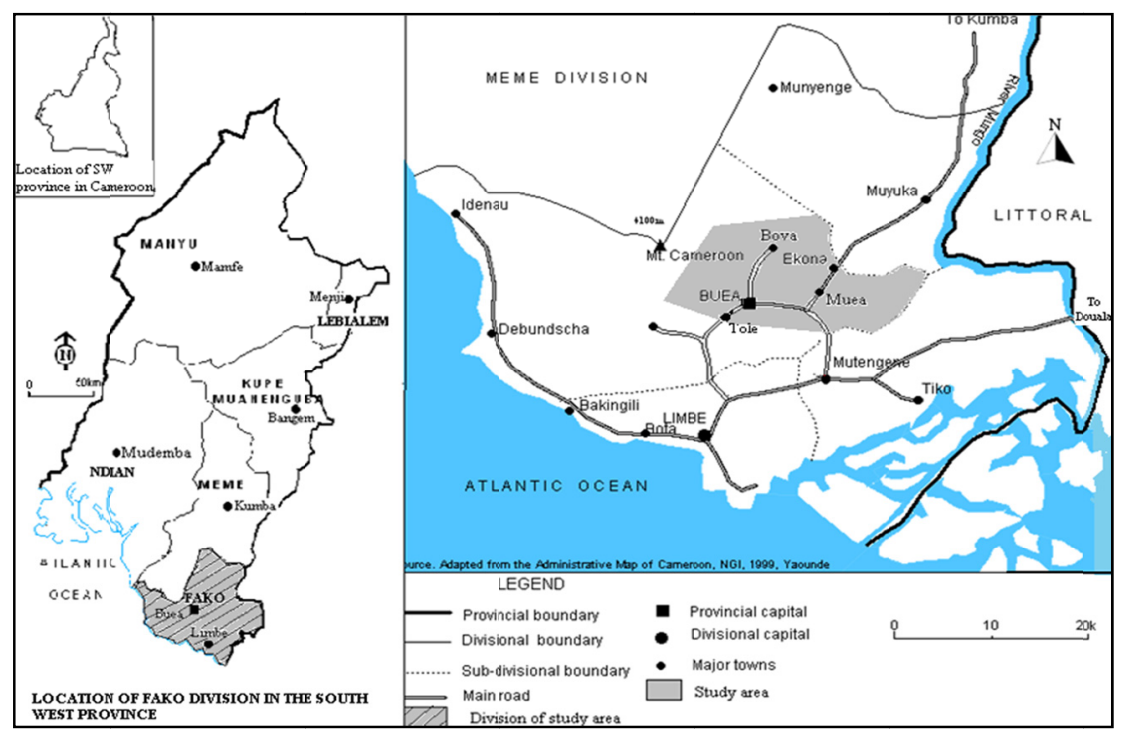

Figure 1. Location of Buea Sub-Division within Fako Division of Cameroon

\subsection{Data Collection and Techniques of Analysis}

A holistic approach was assumed to evaluate the effects of rainfall and temperature on maize output in the Buea Municipality of Cameroon. This study used the standard social science methodology involving data collection and analysis. The data were collected from primary and secondary sources. Primary data were obtained through focused group discussions with maize farmers from which 150 farmers were randomly drawn in order to acquire data relating to their adaptation strategies to the growing variable rainfall and temperature conditions in Buea Sub-Division. Also, interviews were randomly conducted with stakeholders involve in farming activities in the study area such as the agricultural extension workers and some experts in the Buea Sub-Divisional Delegation of Agriculture and Rural Development. This was accompanied by field visits to some maize farms in the area in order to appreciate some of the climatic-oriented problems of maize production and the various adaptation measures used by maize farmers. The information obtained from these sources centred on the various adaptation measures of maize farmers to the growing annual and seasonal variability in the climatic conditions of rainfall and temperature.

Secondary data sources were equally consulted. In this regard, data on the seasonal and annual yields of maize were obtained from the Divisional Delegation of Agriculture and Rural Development for Buea Sub-division. These data were used to establish the seasonal and average trend and average maize yields within the study area. This government establishment equally provided secondary data relating to the seasonal prevalence of pests and diseases affecting maize production in the area. Furthermore, data on climatic records on rainfall and temperature were obtained from the Cameroon Development Corporation (CDC) Head Office at Bota which records climatic parameters in the different locations within the Mount Cameron Area. The study equally relied significantly on secondary data sources related to the trend study of climatic behaviour of the Mount Cameroon Region in general (Fraser et al., 1998; Orock, 2011; Nkemasung, 2014). These data were equally used in establishing the rate of fluctuations in the climatic parameters using the coefficient of variations, anomalies, and averages. The results were used to establish, through logistic regression analysis, the extent to which the fluctuations in these climatic parameters affect maize yields within this humid and montane tropical environment.

The collected data were analysed quantitatively using statistical software packages such as 2010 Microsoft Excel for linear trend analysis, averages, and the Person Product Moment Correlation Coefficient to establish the relationship between variations in maize yields and changes in hectares of farm land cultivated. Logistic regression analyses on the seasonal and annual hydro-climatic effects on cereal yields were done using the Stata 10 statistical software. These correlation coefficient and regression analyses were statistically tested at $95 \%$ level of significance with a threshold probability of 0.05 for the cereals considered in the study. The results of these analyses were presented in tables and figures. 


\section{Results and Discussion}

\subsection{An Analysis of the Climatic Conditions over Buea}

A number of studies have been conducted on the prevailing climatic conditions over Buea Sub-Division and beyond (Fraser et al., 1998; Orock, 2011; Nkemasong, 2014). Buea Sub-Division is found within the humid tropical region with characteristics of the A-climatic type according to the Koppen Classification System. This gives the study area two distinctive seasons; the long rainy season which ranges from mid-March to mid-November, and the short four months dry season expanding from mid-November to Mid-March. The high annual mean minimum and maximum temperatures of $18{ }^{\circ} \mathrm{C}$ and $28{ }^{\circ} \mathrm{C}$ respectively give an annual average temperature of $23{ }^{\circ} \mathrm{C}$ and a narrow temperature range of $10{ }^{\circ} \mathrm{C}$. Rainfall trend analysis using simple regression show a general decline in rainfall amounts over the years with more negative deviations observed since the beginning of the $21^{\text {st }}$ Century (Figure 2).

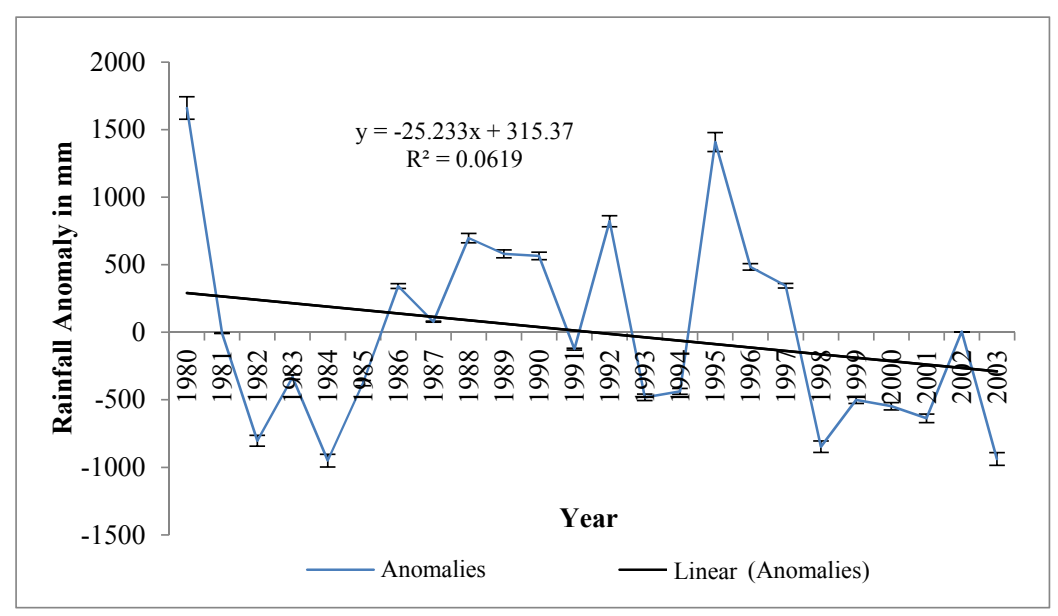

Figure 2. Rainfall anomaly in Buea Sub-Division

Source: CDC Meteorological Station (2014).

The climate of Buea is significantly determined by a combination of global, regional and local factors which are related to the Walker Circulation Models and the seasonal movement of the Inter-tropical Convergence Belt over West and Central Africa respectively. The local conditions which significantly shape the climatic conditions over Buea include the relief factor arising from the sharp rising of the Mount Cameroon from the Atlantic Ocean, the high intensity of the Warm Guinea Currents and dense primary and secondary vegetation cover. These local factors are determined by the proximity of the study area (with an average distance of 36 kilometres) opposite the expansive Atlantic Ocean in the south. These factors combine to make the area a high energy environment characterised by high temperatures of over $24^{\circ} \mathrm{C}$ and high mean rainfall amounts of over $2500 \mathrm{~mm}$ (Fraser et al., 1998; Nkemasong, 2014). These results on temperature behaviour in Buea in particular and the Mount Cameroon Region in general show a general trend of warming (Figure 3) since the dawn of the $20^{\text {th }}$ Century. These results are in accordance with those at the regional level such as across maize mega environments within sub-Saharan Africa conducted at the country level (IPCC, 2007; Burke et al., 2009). 


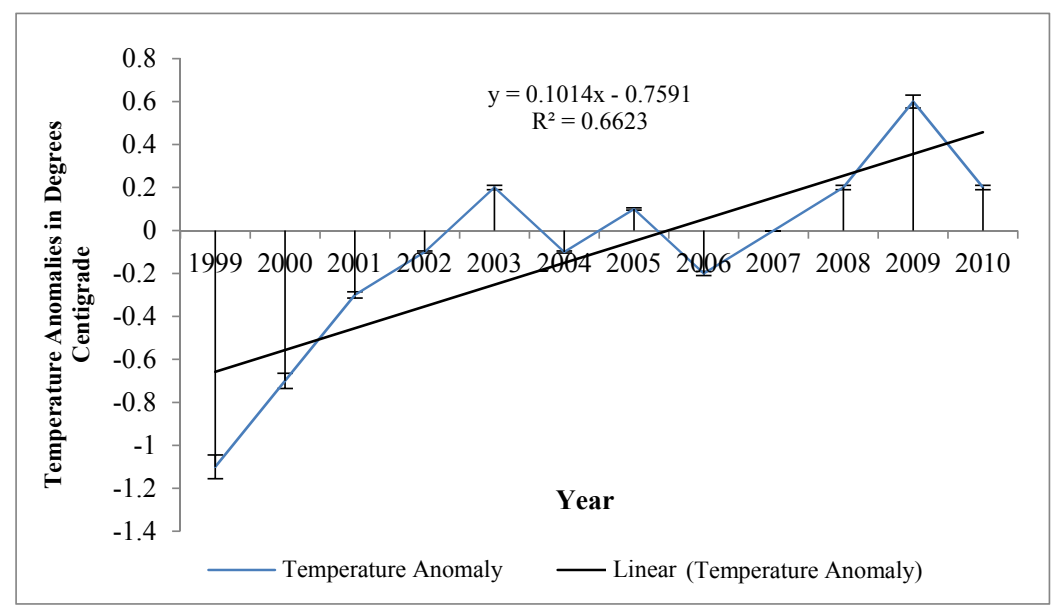

Figure 3. Temperature variability in Buea Sub-Division

Source: CDC Meteorological Station (2014).

\subsection{Maize Production in Buea}

Maize is one of the most widely produced crops in Buea Sub-Division. This is attributed to the fact that unlike other crops, maize plant does not require much care especially at the maturity stage. Maize cultivation is often done in two main seasons in the course of the year. The first season which is the main season use to run from the $3^{\text {rd }}$ week of March to the last week of June while the minor season use to run from the last week of July to the $3^{\text {rd }}$ Week of October. However, with growing climatic oscillations, the sowing season has been shifted due to the late sensation of the rains to the last week of April for the main maize season, and to the first two to three weeks of August for the second season of maize cultivation. The results have been that, since the second season of 2011, maize yields have been observed to be greater during the second season as opposed to the main season situation (Figure 4). Although total and mean output of yields have remained high in the main season when compared to statistics for the second season (Table 1), the trend analyses between 2006 and 2013 show that with continuous climatic variability, the trend is going to be reversed.

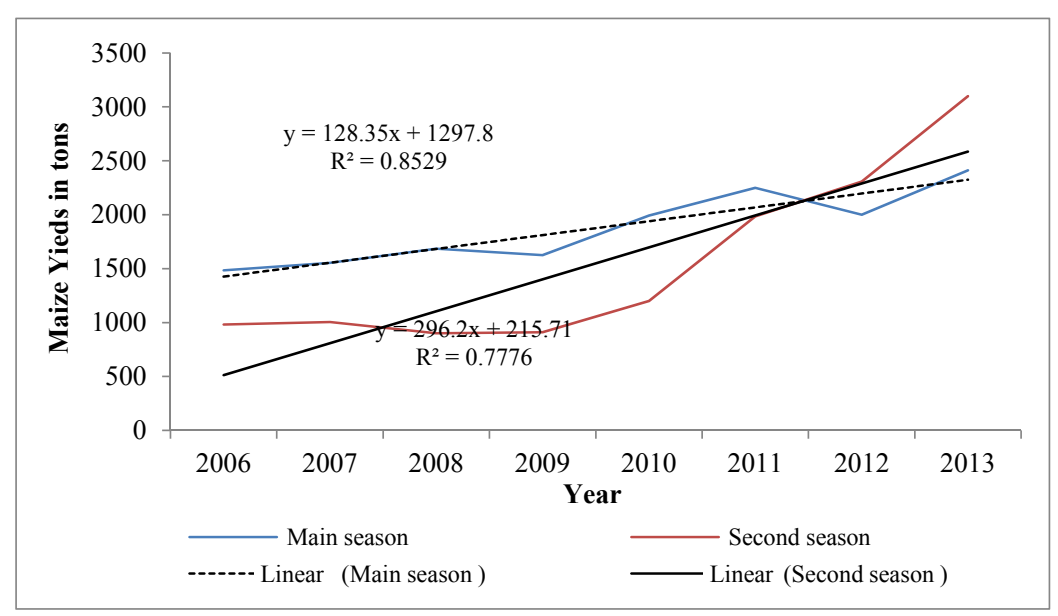

Figure 4. Variations and trends of seasonal maize yields over Buea over the last 8 years

It should be remarked that this reversal situation in maize yields between the main season and second season is not directly linked to the role of climatic parameter. Instead, the uncertainties in the sensation of the rains especially during the main season have made some farmers to engage more hectares of farmlands for the cultivation of crops which require less moisture as it is the case with market gardening crops such as tomatoes and vegetables. This accounts for the gradual increase in the hectares of land cultivated with maize during the second season as opposed to the main season. Although there is a positive relationship between maize yields and 
hectares cultivated during the main season, this relationship is not statistically significant (Table 1). On the contrary, the relationship between the second season and annual yields and their respective hectares cultivated is strongly positive (0.9 and 0.97 respectively) and statistically significant.

Table 1. Statistical summaries of data on maize yields and hectares cultivated

\begin{tabular}{llll}
\hline Parameter & Main season & Second season & Annual \\
\hline Total: Yields in tons & 15003 & 12389 & 27392 \\
Hectares & 4639 & 4580 & 9219 \\
Mean: Yields in tons & 1875.4 & 1548.6 & 3424 \\
$\quad$ Hectares & 579.9 & 572.5 & 1152.4 \\
\hline Correlation Coefficient & 0.51 & 0.90 & 0.97 \\
Degree of Freedom & 6 & 6 & 6 \\
Calculated T-value & 1.5 & 4.93 & 9.7 \\
Probability Value & 2.45 & 2.45 & 2.45 \\
Conclusion & Not significant & Significant & Significant \\
\hline
\end{tabular}

Note. 0.05 level of significance.

\subsection{Climatic Impacts on Maize Yields}

The observed oscillations in rainfall and temperature could have direct and indirect implications for maize production. On seasonal basis, the unreliability in the beginning of the rains and the reductions in rainfall amounts are observed to have negative impacts on maize yields putting aside other confounders such as reductions in hectares of maize cultivated lands during this season. Decreasing rainfall amounts combined with increasing temperatures have implications for maize production especially in relation to soil moisture and pests-diseases prevalence. The growing erratic nature in the beginning and progress in rainfall amounts have reduced the number of maize growing days. This has therefore resulted in the qualitative reduction in maize yields. Although the analysis on maize trends show an increasing trend, it is important to remark that this increase is related to increases in the number of hectares cultivated and not the qualitative improvements in maize yields. This is why a negative relationship which is not statistically significant has been observed between oscillations in rainfall and temperature, and maize production (Table 2). This negative relationship must have thus occurred by chance. However, a positive and statistically significant relation is observed between changes in the number of hectares cultivated and the yields of maize (Tables 1 and 2).

Table 2. Analysis of multiple regressions on the effects of variations in rainfall, temperature and hectares on maize yields

\begin{tabular}{lllll}
\hline Maize Yields & Coefficient & $\mathrm{t}$ & $\mathrm{P}>\mathrm{t}$ & [95\% Conf. Interval] \\
Association with: & -0.2897714 & -0.97 & 0.388 & $-1.12-0.54$ \\
\hline Rainfall & -11.19685 & -0.02 & 0.986 & $-1641.75-1619.36$ \\
Temperature & 3.330709 & 7.54 & 0.002 & $2.11-4.56$ \\
Hectares & & & \\
\hline
\end{tabular}

The occurrence by chance of the relationship between rainfall amounts and maize yields has been justified by field surveys through observations and interviews which reveal that the uncertainties in the beginning of the rains and the increasing temperatures have gradually shifted the sowing period from the historical third week of March to the last week of April and sometimes the first week of May which receive minimum optimal soil moisture amounts necessary for maize germination and growth. This often reduces the growing maize season by some four to five weeks thus resulting in a decline in maize yields as reported by $75 \%$ of the sample farmers. Such shifts especially in the main maize growing season equally affect the minor maize growing season due to over lapping or concomitant shifts in the sowing season from July and August to the latter half of the month of September. Consequently, this gives just about 6 weeks for maize to grow during this minor season prior to the arrival of the dry season in the Month of November. However, the shifts in the sowing season have resulted to the increase in the maize yields in the minor season much more than the yields in the main season since 2011. 
In some instances, farmers reported extra losses associated with repeated planting particularly during the main season. These were mostly farmers who continue to stick to the traditional sowing period of the third week of March. This is because, by this time, they often erroneously sow in anticipation of the fact that the rains will come at the conventional time. When these rains fail to come at this time, coupled with the high temperatures, the planted seed become dry and dead in the soil thus necessitating repeated planting of the seeds in the last week of April when the rains must have fallen effective enough to increase soil moisture required for maize seed germination and growth. There is thus the need for sensitisation by the various agricultural institutions on the effective period to plant for every season in the midst of these variable rainfall and temperature conditions.

The observed negative relationship between increasing warming and maize yields over Buea have been supported by a number of studies in different parts of the world. Battisti and Naylor (2009) observed that growing season temperatures will exceed the most extreme seasonal temperatures recorded in the past century. As such, with the use of crop production data and climatic records, a $6{ }^{\circ} \mathrm{C}$ increase in temperature during the grain filling period resulted in a 10\% yield loss in the US Corn Belt (Thomson et al., 1966 cited in Cairns et al., n.d.). This has equally been supported by later studies of Dale (1983) cited in (Cairns et al., n.d.) when he showed, in the same region, a negative correlation between maize yields and accumulated degrees of daily maximum temperatures above $32{ }^{\circ} \mathrm{C}$ during the grain filling period. In their study on the use of statistical models in predicting crop yields to climate change in sub-Saharan Africa, Lobell and Burke (2010) suggested that an increase in temperature of $2{ }^{\circ} \mathrm{C}$ would result in a greater reduction in maize yields within sub-Saharan Africa unlike a decrease in precipitation by $20 \%$. In a related study, Lobell et al. (2011) cited in Cairns et al. (n.d.) observed that for every degree day above $30{ }^{\circ} \mathrm{C}$, grain yield was reduced by $1 \%$ and $1.7 \%$ under optimal rainfed and drought conditions, respectively.

Based on these analysis and discussions, it is clear that climatic effects on maize production arising from continuous warming will be greater that those arising from the slight decreases in rainfall amounts observed over Buea. It is therefore necessary that in the research on seed improvements using biotechnology, heat tolerant to heat stress by maize plants should be incorporated in the maize germplasm. In this context, heat stress is considered to be temperatures above a threshold level that results in irreversible damage to crop growth and development (Cairns et al., n.d.). This is usually a function of the intensity, the duration and the rate of increase in temperature. A number of studies support these results on the impact of slight increase of temperatures on maize outputs in Buea, thereby strongly suggesting that maize growing regions of sub-Saharan Africa will encounter increased growing season temperatures and frequency of droughts (IPCC, 2007).

\subsection{Climatic Impacts on Maize Pests and Diseases}

Variability in climatic parameters especially temperatures in Buea do not only affect the anatomical and physiological welfare of the maize plant. They are equally observed to have indirect effects on maize especially through pests and diseases. Given that they do not use their metabolic activities to ensure thermo-regulation, these insects such as stem borers are often classified as poikilothermic (cold blooded), relying significantly on the surrounding environmental temperatures for their activeness. Temperature is thus the single most important environmental factor influencing the behaviour, distribution, development and survival, and reproduction of insect (Cairns et al., n.d.). This is why the life cycle predictions of insects and pests affecting crops are often calculated on accumulated degree days, which is a function of both time and temperature. The rate of propagation of the population of a particular pest or insect is often significantly determined by the extent to which temperatures are increasing or decreasing. In this light, it has been estimated that a $2{ }^{\circ} \mathrm{C}$ increase in temperature has the potential to increase the number of insect life cycles during the crop season by one to five times (Petzoldt \& Seaman, 2005; Bale et al., 2002; Porter et al., 1991 cited in Cairns et al., n.d.). The observed temperature rises and the frequent dry spells in the month of April over Buea have thus been noted to favour the proliferation of insects and related crop damages as well as aflatoxin and fumonisinmy cotoxins in maize. The increasing attacks on maize by these insect-pests and their associated pathogens such as maize streak virus, corn stunt complex that are vectored by different species of leaf hoppers have been attributed to their extensive geographical distribution as a results of global warming.

\subsection{Farmers' Resilience and Adaptations to Oscillating Climatic Conditions in Buea}

Despite the identified as well as the prospective effects of oscillations in rainfall and temperature parameters, food security within the Buea Municipality is guaranteed. This is significantly related to the high diversification of crops cultivated by farmers. Located within the humid and montane tropical environment, the Buea Municipality is ideal for the cultivation of crops of many varieties ranging from cereals, market gardening crops, tubers/root crops, to tree crops. Apart from the above discussed climatic parameters, there are other factors which 
contribute to high crop yields and diversity in the area. Some of these include the rich fertile volcanic soils on the slopes of the Mount Cameroon which is an active strato-volcano and the increase in the use of chemicals in order to minimise pest-disease attacks on crops. Other adaptations are observed through the use of genetically modified hybrid seedlings by some farmers which often mature faster than the traditional maize seeds. However, these genetically modified maize seeds are not used by all the farmers due to cultural inertia. Some farmers noted that they prefer the use of their tradition maize seeds on grounds that the harvested maize is tasteful. No wonder, $90 \%$ of the sampled farmers who plant these genetically modified maize seeds noted that they cultivate maize mostly for commercial purposes and not for home consumption.

Another important adaptation to the erratic rainfall commencement and increasing temperatures is observed through the shifts in the planting dates of maize by farmers (Table 3). A total of $63 \%$ of the surveyed farmers accepted to have shifted their sowing dates of maize from the conventional third week of March to the last week of April during the main season, and from the last week of July to the second week of September during the minor maize growing season. Other adaptation measures include changing the crop types cultivated, and the shift to off farm jobs. The later has been growing given that the increasing urbanisation of the Town of Buea which has been accelerated by the creation of the University of Buea (Ntansi, 2004; Mojoko, 2011) has provided jobs in the formal and informal sectors. A total of $19.2 \%$ of the respondents noted that with the off farmers opportunities associated with the urbanisation of Buea, they have been largely engaged in these job opportunities. Some of them only receive incomes from farming activities through the renting of their farms to those who can continue cultivating crops on them in the midst of the erratic rainfall beginnings and increasing temperatures. However, the rate at which these adaptation measures will continue to be sustainable in the next 50 years in the face of changing climatic patterns will significantly depend on extension services to and farmers' access to credit and secured land tenures.

Table 3. Sampled farmers' responses to the various adaptation strategies to erratic rainfall commencement and increasing temperatures in Buea Sub-Division

\begin{tabular}{lll}
\hline Adaptation Measure & Erratic Beginning of Rains (\%) & Increasing temperature (\%) \\
\hline Diversification of Crop & 25.5 & 14.3 \\
Change of planting date & 45 & 17 \\
Find off-farm jobs & 10.2 & 9 \\
Farm size reduction & 1 & 1.1 \\
Change of crops & 4 & 8.7 \\
Planting of short-season variety & 12.1 & 13.9 \\
No adaptation & 2.2 & 48 \\
Total & 100 & 100 \\
\hline
\end{tabular}

\section{Conclusion}

The humid equatorial and montane climatic conditions that characterised the Buea Municipality provide ideal conditions for the growth of maize which is widely consumed in varied forms by the population. However, the spatio-temporal inconsistencies in climatic conditions continue to dictate, amongst other factors, the pace of crop production in general and maize cultivation in particular. This is more so because the variations in the different climatic elements (especially soil moisture from rainfall and temperature) usher in different effects on maize yields. In this light, the observed slight reductions in rainfall and the increasing temperatures (Nkemasong, 2011) in the Mount Cameroon Region as a whole have brought about significant reductions in maize yields particularly in during the first season of cultivation. On the contrary, these effects have increased maize yields during the second season which is considered as a subsidiary season of cultivation. In the face of these effects, farmers on their part have developed a series of adaptation strategies even though some of them are simply makeshift adaptations. If there are concerns about ensuring food security in the region as well as the Central African Region as whole, then there is the need for expert intervention in order to empower the farmers on robust adaptation measures. Such efforts should focus among other things on the need for the development of new maize varieties alongside improved management options and other agricultural innovations. In a retrospective survey, the use of new varieties alongside improved management options showed to have counteracted maize yield losses by up to $40 \%$ (Thornton et al., 2009). 


\section{References}

Battisti, D. S., \& Naylor, R. L. (2009). Historical warnings of future food Insecurity with unprecedented seasonal heat. Science, 323, 240-244. https://doi.org/10.1126/science.1164363

Burke, M. B., Lobell, D. B., \& Guarino, L. (2009) Shifts in African crop climates by 2050, and the implications for crop improvements and genetic resources conservation. Global Environ. Change, 19, 317-325. https://doi.org/10.1016/j.gloenvcha.2009.04.003

Cairns, J. E., Sonder, K., Zaidi, P. H., Verhulst, N., Mahuku, G., Babu, R., ... Prasanna, B. M. (n.d.). Maize production in a changing climate: Impacts, adaptation and mitigation strategies.

Charity, M., Shakespear, H., \& Lawrence, M. (2013). The Effects of Climate Change and Variability on Food Security in Zimbabwe: A Socio-Economic and Political Analysis. International Journal of Humanities and Social Science, 3(6), 270-286.

FAO. (2007). Adaptation to Climate Change in Agriculture, Forestry and Fisheries: Perspective, Framework and Priorities. Food and Agriculture Organization of the United Nations Rome. Retrieved from ftp://ftp.fao.org/docrep/fao/009/j9271e/j9271e.pdf

FAOSTAT. (2010). FAO Statistical Database. Food and Agricultural Organization of the United Nations (FAO). Retrieved from http://faostat.fao.org

Fosu-Mensah, B. Y. (2012). Modelling Maize (Zea mays L.) Productivity and Impact of Climate Change on Yield and Nutrient Utilization in Sub-Humid Ghana. In P. L.G. Vlek (Ed.), Ecology and Development Series (No. 87).

Fraser, P. J., Hall, J. B., \& Healey, J. R. (1998). Climate of the Mount Cameroon Region. Long and Medium Term Rainfall, Temperature and Sunshine Data, University of Wales, Bangor, Mount Cameroon Project and Cameroon Development Corporation, School of Agriculture and Forest Sciences Publication Number 16.

Inter-Governmental Panel on Climate Change (IPCC). (2007). Summary for Policymakers. Working Group II Climate Change 2007: Climate Change Impacts, Adaptation and Vulnerability. IPCC, Geneva.

Inter-Governmental Panel on Climate Change (IPCC). (2009). Fourth Assessment Report: Synthesis. Retrieved November 17, 2007, from http://www.ipcc.ch/pdf/assessment-report/ar4/syr/ar4_syr.pdf

International Food Policy Research Institute (IFPRI). (2006). How Will Agriculture Adapt to a Shifting Climate? IFPRI Forum, December, 2006.

Lambi, C. M., \& Molua, E. L. (2007). The Economic Impact of Climate Change on Agriculture in Cameroon. World Bank Policy Research Working Paper No. 4364. Retrieved from http://papers.ssrn.com/sol3/ papers.cfm?abstract_id $=1016260$

Lobell, D. B., \& Burke, M. B. (2010). On the Use of Statistical Models to Predict Crop Yield Responses to Climate Change. Agric. Forest Metero., 150, 1443-1452. https://doi.org/10.1016/j.agrformet.2010.07.008

Mojoko, F. M. (2011). Urban Development in Fako Division (Unpublished M.Sc. Thesis). Department of Geography, University of Buea.

Nelson, G. C., Rosegrant, M. W., Koo, J., Robertson, R., Sulser, T., Zhu, T., ... Lee, D. (2009). Climate Change Impact on Agriculture and Costs of Adaptation. Food Policy Report. Washington, D.C: International Food Policy Research Institute.

Nkemasong, N. A. (2014). Climate Variability and Implications on Hydrological Systems within the Southern Volcanic Province of Cameroon (Unpublished Ph.D. Thesis). Department of Geography, University of Buea, Cameroon.

Orock, F. T. (2011). Wetland Utilisation, Problems and Management on the North Eastern and Southern Slopes of Mount Cameroon (Unpublished Ph.D. Thesis). Department of Geography, University of Buea, Cameroon.

Rosenzweig, C., \& Hillel, D. (1995). Potential Impacts of Climate Change on Agriculture and Food Supply. Consequences, 1(2). Retrieved May 12, 2011, from http://www.gcrio.org/CONSEQUENCES/summer95/ agriculture.html

Tata, E. S., \& Lambi, M. C. (2015). Hydro-Climatic Implications on Market Gardening Production in the Bui-Noketunjia Wetlands. African Journal of Social Sciences, 6(2), 4-17. 
Thornton, P. K., Jones, P. G., Alagarswamy, G., \& Andersen, J. (2009). Spatial variation of crop yield response to climate change in East Africa. Global Environ. Change, 19, 54-65. https://doi.org/10.1016/ j.gloenvcha.2008.08.005

Tosam, H. N. (2012). An Analysis of Spatial Population Pattern and the Provision of Socio-Economic Infrastructure in Buea Sub-Division. African Journal of Social Sciences, 3(1), 116-128.

\section{Copyrights}

Copyright for this article is retained by the author(s), with first publication rights granted to the journal.

This is an open-access article distributed under the terms and conditions of the Creative Commons Attribution license (http://creativecommons.org/licenses/by/4.0/). 